\title{
How do invasive species travel to and through urban environments?
}

\author{
Ashlyn L. Padayachee • Ulrike M. Irlich • Katelyn T. Faulkner • \\ Mirijam Gaertner • Şerban Procheş $\cdot$ John R. U. Wilson (i) - Mathieu Rouget
}

Received: 25 May 2017/Accepted: 15 August 2017/Published online: 30 October 2017

(C) Springer International Publishing AG 2017

\begin{abstract}
Globalisation has resulted in the movement of organisms outside their natural range, often with negative ecological and economic consequences. As cities are hubs of anthropogenic activities, with both highly transformed and disturbed environments, these areas are often the first point of entry for alien species. We compiled a global database of cities with more than one million inhabitants that data had on alien species occurrence. We then identified the most prominent pathways of introduction and vectors of
\end{abstract}

Guest Editors: Mirijam Gaertner, John R.U. Wilson, Marc W. Cadotte, J. Scott MacIvor, Rafael D. Zenni and David M.

Richardson/Urban Invasions.

Electronic supplementary material The online version of this article (doi:10.1007/s10530-017-1596-9) contains supplementary material, which is available to authorized users.

A. L. Padayachee $(\bowtie) \cdot$ Ş. Procheş

School of Agriculture, Earth and Environmental, Discipline of Geography, University of KwaZulu-Natal, Westville Campus, Durban 4000, South Africa e-mail: ashlyn.levadia@gmail.com

A. L. Padayachee · K. T. Faulkner - J. R. U. Wilson South African National Biodiversity Institute, Kirstenbosch Research Centre, Claremont 7735, South Africa

U. M. Irlich

Centre for Invasion Biology, Environmental Resource Management Department (ERMD), City of Cape Town, Westlake Conservation Office, Ou Kaapse Weg, Tokai, Cape Town 7966, South Africa spread of alien species in these cities. Most species were intentionally introduced to cities and were released or escaped from confinement. The majority of alien species then spread within cities through natural means (primarily unaided dispersal). Pathway prominence varied across the taxonomic groups of alien species: the most prominent pathway for plants and vertebrates was the escape pathway; for invertebrates the stowaway and contaminant pathways were most likely to facilitate introductions. For some organisms, pathway prominence varied with the geographical and climatic characteristics of the city. The characteristics of the cities also influenced the prominence of vectors of spread for alien species. Preventing the natural spread of alien species within cities, and into adjacent natural environments will be, at best, difficult. To prevent invasions, both the

\author{
K. T. Faulkner \\ Department of Zoology and Entomology, Centre for \\ Invasion Biology, University of Pretoria, Hatfield 0028, \\ South Africa \\ M. Gaertner · J. R. U. Wilson \\ Centre for Invasion Biology, Department of Botany and \\ Zoology, Stellenbosch University, \\ Private Bag X1, Matieland 7602, South Africa \\ M. Gaertner \\ Nürtingen-Geislingen University of Applied Sciences \\ (HFWU), Schelmenwasen 4-8, 72622 Nürtingen, \\ Germany
}


intentional and unintentional introduction of potentially harmful alien species to cities must be prevented. The pathways of introduction and vectors of spread identified here should be prioritised for management.

Keywords Biological invasions - Pathways of introduction · Prioritisation - Urban invasions . Vectors of spread

\section{Introduction}

The increase in world trade, travel and tourism has resulted in a plethora of mechanisms for organisms to be transported outside of their natural ranges (Wilson et al. 2009; Blackburn et al. 2011; Gallardo and Aldridge 2013; Essl et al. 2015; Gotzek et al. 2015). The negative ecological, economic and social implications of the establishment of alien species are widely recognised (Pimentel et al. 2001; Kenis et al. 2009; Vila et al. 2010). Once introduced to a new location, alien species (sensu Richardson et al. 2000) must overcome a series of barriers to successfully invade these environments (Blackburn et al. 2011). The framework proposed by Blackburn et al. (2011) depicts an introduction-naturalization-invasion continuum. The "transport" and "introduction" stages of the invasion continuum refer to the initial dispersal of an alien species to a new location (Puth and Post 2005; Blackburn et al. 2011). Initial dispersal is imperative as the sequential stages of the invasion continuum are contingent upon this stage (Puth and Post 2005; Blackburn et al. 2011). Strategies that prevent the introduction of alien species often prove to be more cost effective than those that respond to incursions (Hulme 2006; Pyšek and Richardson 2010; Kumschick and Richardson 2013; Faulkner et al. 2016a). McGeoch et al. (2016) suggest that to effectively manage invasions, the prioritisation of species, their pathways of introduction, and the sites which are most at risk of invasion is essential.

The most prevalent and well-developed prioritisation approach is one that focuses prevention and management efforts on specific, high-risk species. This approach identifies alien species (often using

M. Rouget

UMR PVBMT, CIRAD, Saint-Pierre, La Réunion, France traits that may be related to invasion success) which are likely to have negative environmental and socioeconomic impacts where introduced (McGeoch et al. 2016). However, for unintentional introductions, this approach is not feasible. This is because it is difficult to predict which species will arrive, as there are a vast number of species that could be unintentionally introduced, and as the biology and life history of species potentially introduced are sometimes poorly known (Leung et al. 2014; McGeoch et al. 2016).

Site-based prioritisation focuses on sites that are susceptible (i.e., most exposed to invasions) and sensitive (i.e., most vulnerable to impacts of invasions), as determined by their geographical, ecological and climatic characteristics (McGeoch et al. 2016). Because of concentrated anthropogenic activities, cities are characterised by high levels of disturbance, high transport intensity, and high environmental heterogeneity (Hansen and Clevenger 2005); they are thus both susceptible and sensitive to invasions.

Pathways of introduction are the processes that lead to the introduction of an alien species from one geographical location to another (Richardson et al. 2010). The pathway approach focuses on identifying the pathways that facilitate the introduction of alien species, with the aim of reducing the number of alien species (i.e., colonisation pressure) and individuals (i.e., propagule pressure) introduced (Hulme et al. 2008; Reaser et al. 2008; Katsanevakis et al. 2013; Pergl et al. 2017). As specific taxa do not need to be identified (Katsanevakis et al. 2013), this approach is particularly valuable where taxon-specific control efforts are not possible, for example, for unintentional introductions (Woodford et al. 2016). However, due to the voluminous nature of the pathways and their economic importance, implementation can be legislatively and practically difficult. Therefore, to implement this approach successfully the prioritisation of the pathways of introduction is fundamental. The Convention on Biological Diversity (CBD), which assigns global priorities and guidelines regarding invasive alien species through Aichi Target 9, requires parties (countries) to identify and prioritise their pathways of introduction by 2020 (Blackie and Sunderland 2015; Scalera et al. 2016).

Recent studies have described and categorised the pathways of introduction (Hulme et al. 2008; Essl et al. 2015; Faulkner et al. 2016a), but most of these studies have either focused on how alien species are 
introduced to natural systems or have evaluated pathways at larger scales (globally or nationally) (Hansen and Clevenger 2005; Katsanevakis et al. 2013). Far less attention has been given to urban invasions and how species are being introduced to and spreading within cities. Cities present a complex network of vectors that facilitate alien species movement-both within these environments, and subsequently into surrounding, natural areas (von der Lippe and Kowarik 2008; McLean et al. 2017). In this study the term 'pathways of introduction' refers to the processes that lead to the introduction of an alien species to a city, whereas 'vectors of spread' refers to the processes through which alien species spread after introduction to a city.

We identify the prominent pathways of introduction and vectors of spread for cities and evaluate whether these pathways and vectors vary across (1) taxonomic groups, and for cities with different (2) geographical and (3) climatic characteristics. By identifying the most prominent pathways of introduction and vectors of spread in urban environments we hope to inform management decisions concerning the prevention of the introduction and spread of alien species.

\section{Methods}

\section{Data collection}

To evaluate the prominence of the pathways of introduction and the vectors of spread in cities, we (1) selected cities to use as study sites, (2) obtained information on the geographical and climatic characteristics of the cities, (3) identified the alien species present in each city, and (4) determined the pathways of introduction and vectors of spread of these species.

\section{Selection of cities}

Human population affects the pressures exerted on cities to provide natural and economic resources for inhabitants. Therefore, human population estimates were used to select cities. Only cities with a population of $\geq 1,000,000$ were selected for this study (i.e. 498 cities; Demographia 2014, UN 2014). Furthermore, as we are using alien species occurrence data from the Global Biodiversity Information Facility (GBIF)
(GBIF 2016-Accessed 1 December 2016), cities in countries not affiliated to the GBIF were excluded to reduce data biases. Lastly, we excluded all cities with no alien species records. Based on these characteristics, 167 cities were selected (Fig. 1).

\section{City characteristics}

We collected geographical and climatic data for the selected cities. Coastal and inland cities were identified to ascertain the differences in the prominence of pathways of introduction and vectors of spread for cities with or without maritime ports. Climate affects the establishment of alien species in new locations (Ficetola et al. 2009), therefore we categorised cities into broad climate zones (equatorial, arid, warm temperate and snow climates) according to the Köppen-Geiger climate classification (Kottek et al. 2006).

\section{Alien species selection and distribution}

Alien species records were extracted from the Global Invasive Species Database (GISD), an online inventory of invasive alien species. The database provides information on the pathways of introduction and vectors of spread of the listed species, categorised using standardised classification systems (GISD 2016 - accessed 8 June 2016). We extracted all alien species records for which information on the pathway of introduction was available in the GISD (1124 records). In the GISD, information regarding the introduction location of the alien species was recorded for only a portion (282 records) of the species and was inconsistently recorded (i.e., in some cases countries were listed, but in other cases cities or provinces). Therefore, to ascertain the introduced range of the alien species in the GISD, we searched for each species in the Global Register of Introduced and Invasive Species (GRIIS) (2016-accessed 15 November 2016). The GRIIS database provides the introduced range of alien species at country level. Because of this coarse classification, some species were listed as either native or alien to specific countries (e.g., Acacia mearnsii in Australia) without further details provided in the database. In these cases, we recorded species as present in cities based on known introduced populations present in the particular city. We then downloaded occurrence data for each 


\section{N}

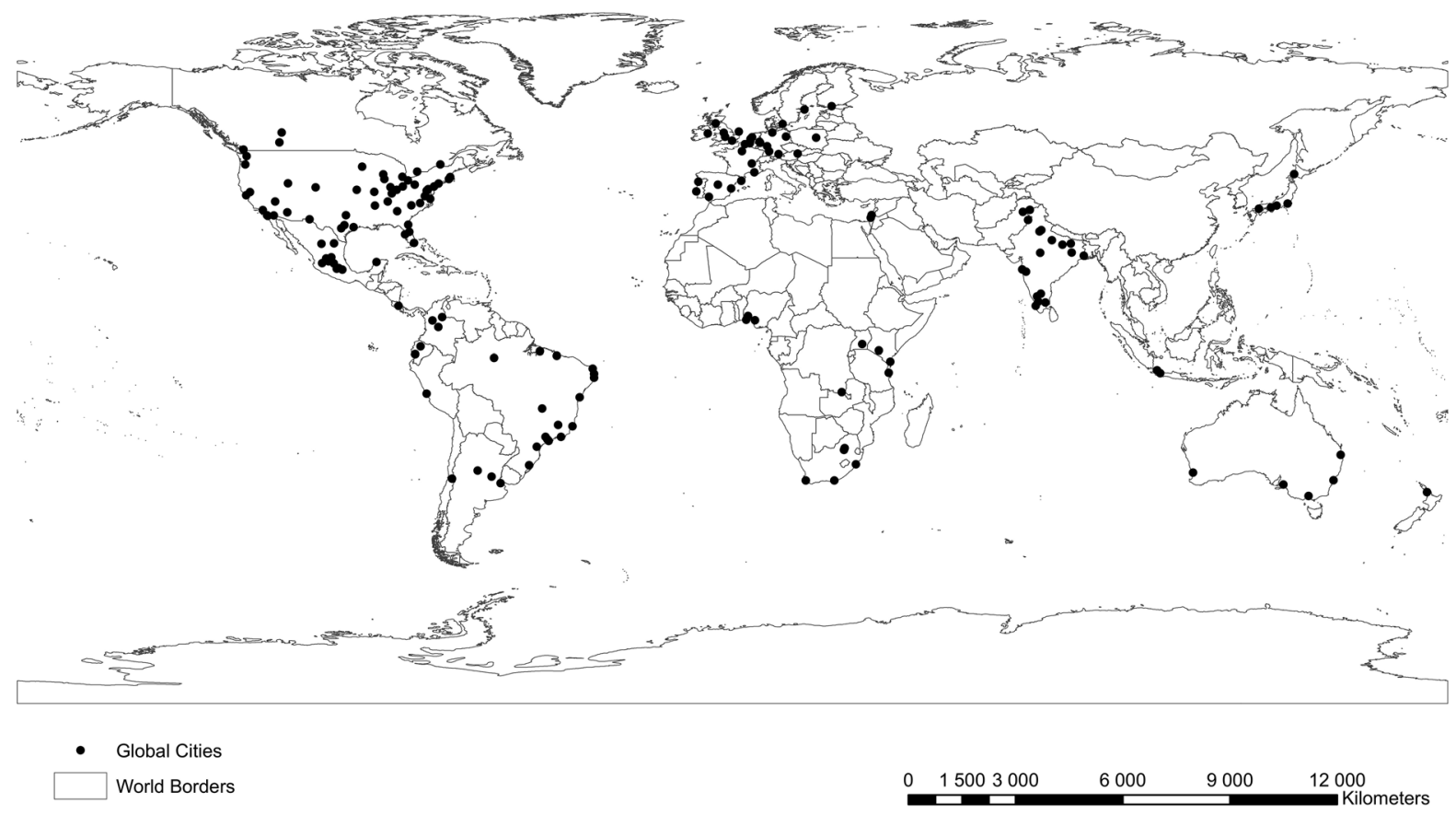

Fig. 1 Map of the global cities selected for the analysis of pathways of introduction and invasion. The selected cities had more than one million inhabitants, were in countries affiliated to the Global Biodiversity Information Facility, and had data on alien species occurrence

species' introduced range from the GBIF (2016accessed 1 December 2016), assuming that records of species in their native range would thus be excluded from our dataset. Furthermore, we excluded all occurrence records for which the source of the record was unknown in GBIF. We mapped the occurrence records from the alien species' introduced ranges using ArcGIS ArcMap 9.3 (ESRI 2006) and identified the alien species that have been introduced to our preselected cities. A total of 255 alien species were recorded as present in our preselected cities.

\section{Pathway and vector data collection}

Hulme et al. (2008) developed a framework which outlines, based on varying levels of human mediation, six principal pathways of introduction (release, escape, contaminant, stowaway, corridor and unaided). This framework has since been modified to form the hierarchical classification system that has been adopted by the CBD (Scalera et al. 2016) (Table 1). Alien species records containing pathway information (1124 records) were extracted from the GISD and were classified using the CBD's hierarchical system. We recorded all potential pathways of introduction for alien species present in our selected cities. Additionally, the GISD provides information regarding vectors of spread (local dispersal methods) of alien species in introduced locations (GISD 2016). Some pathway sub-category names in the GISD data overlapped with those of the listed vectors; however, here we dealt with pathway and vector data separately. We renamed vectors for ecologically accurate interpretation (e.g., natural dispersal, endo- and exozoochory can all be considered as natural dispersal, therefore we renamed natural dispersal as unaided dispersal-see Table 2), and we classified vectors as intentional, unintentional and natural to emphasise the importance of human-mediation (Scalera et al. 2016). However, water currents were not so easily discerned. The GISD does not specify if water bodies are natural or man-made systems, and as such we classified water currents as unintentional or natural dispersal to account for this uncertainty (Table 2). We recorded 
Table 1 List of the six principal pathways of introduction and the subcategories, used in this study, within each pathway category as recognized in the CBD scheme (Hulme et al. 2008; Scalera et al. 2016)

\begin{tabular}{|c|c|}
\hline Pathway abbreviation & Pathway name \\
\hline$R$ & Release \\
\hline Release.nature & Release in use for nature \\
\hline Biol.control & Biological control \\
\hline Eros.dune.stab & Erosion control and dune stabilisation \\
\hline Fishery.wild & Fishery in the wild \\
\hline Hunting.wild & Hunting in the wild \\
\hline Lands.flora.fauna & Landscape; flora and fauna improvement \\
\hline$E$ & Escape \\
\hline Agriculture & Agriculture \\
\hline Aqua.mariculture & Aquaculture or mariculture \\
\hline Bot.zoo.aquaria & Botanical gardens; zoos or aquaria \\
\hline Farmed animals & Farmed Animals \\
\hline Forestry & Forestry \\
\hline Fur farms & Fur Farms \\
\hline Horticulture & Horticulture \\
\hline Ornamental.purp & Ornamental purposes \\
\hline Pet.terr.species & Pet; aquarium; or terrarium species \\
\hline Other.contam & Other escape from confinement \\
\hline Research & Research (in facilities) \\
\hline Live.food.bait & Live food and live bait \\
\hline$S$ & Transport-Stowaway \\
\hline Container.bulk & Container or bulk \\
\hline Hitchhikers.plane & Hitchhikers on a plane \\
\hline Hitchhikers.boat & Hitchhikers on a ship or boat \\
\hline Machinery.equip & Machinery or equipment \\
\hline People.luggage & People and their luggage \\
\hline Ballast.water & Ship or boat ballast water \\
\hline Hull.fouling & Ship or boat hull fouling \\
\hline Vehicles & Vehicles \\
\hline Other.transport & Other means of transport \\
\hline Fish.aqauculture & Angling, fishing, aquaculture equipment \\
\hline Org.pack.mat & Organic packing material \\
\hline$C$ & Corridors \\
\hline Waterways.seas & Interconnected waterways; basins or seas \\
\hline Unknown & Unknown \\
\hline
\end{tabular}

all potential vectors of spread for alien species present in our selected cities.

\section{Analysis}

We classified the alien species as invertebrates (42 species), plants (152 species), and vertebrates (61 species) to investigate whether the prominence of the pathways varies across taxonomic groups (see Online Resource 1-Supplementary Statistics for the number of species sub-groups of alien species in each taxonomic group). We then merged the pathway and vector datasets with the geographical and climatic information contained in the cities database (see Online Resource 2 for full dataset).

The pathway and vector data were tabulated to yield counts of the number of alien species whose introduction or spread has been facilitated by the various pathways and vectors. However, prior to conducting statistical analyses, inconsistent records 
Table 2 List of the vectors of spread and abbreviations. Listed are the vectors as renamed for ecologically accurate interpretation, with original names as they appear in the GISD (2016) in parentheses. Vectors were classified as "intentional",

"unintentional" and

"natural" based on the degree of human-mediation

\begin{tabular}{|c|c|c|}
\hline Vector abbreviations & Vector name (original name) & Classification \\
\hline Ornament & Ornamental & Intentional \\
\hline Unaided & Unaided (natural dispersal) & Natural \\
\hline Water.curr & Water currents & Unintentional/natural \\
\hline Wind.disp & Wind dispersed & Natural \\
\hline Road.veh & Road vehicles & Unintentional \\
\hline Hab.mater & Transportation of habitat material & Unintentional \\
\hline Agriculture & Agriculture & Intentional \\
\hline Boats & Boats & Unintentional \\
\hline Other & Other & Unknown \\
\hline Mach.equip & Translocation of machinery or equipment & Unintentional \\
\hline Endozoo & Endozoochory (consumption or excretion) & Natural \\
\hline Gard.esc & Garden escapes or waste & Unintentional \\
\hline Disturb & Disturbance & Unintentional \\
\hline Exozoo & Exozoochory (on animals) & Natural \\
\hline Clth.foot & Clothing or footwear & Unintentional \\
\hline Hike.wear & Hikers clothing or boots & Unintentional \\
\hline Off-rd.veh & Off-road vehicles & Unintentional \\
\hline Aquacul & Aquaculture & Intentional \\
\hline Esc.confin & Escape from confinement & Intentional \\
\hline Resr.share & Resource sharing & Unintentional \\
\hline Acclim & Acclimatization societies & Intentional \\
\hline Forestry & Forestry & Intentional \\
\hline Horticul & Horticulture & Intentional \\
\hline Intentional & Intentional release & Intentional \\
\hline Veg.rep & Vegetative reproduction & Unintentional \\
\hline Forg.resor & Foraging for resources & Unintentional \\
\hline Land.fauna & Landscape and fauna improvement & Intentional \\
\hline Live.food & Live food trade & Intentional \\
\hline Nurs.trade & Nursery trade & Intentional \\
\hline
\end{tabular}

were removed from the dataset. For example, all records lacking species-level identification were excluded from the analyses (e.g., all Didemnum spp. and Pinus spp. were listed at a genus-level). We also excluded all species which were not present in the GRIIS and GBIF databases, as well as fungi, viruses and other pathogens (only plants and animals were included). Based on the data available in the GISD at the time of data collection, no species had moved unaided from one non-native region to another (Saul et al. 2016) and, therefore, the unaided pathway was excluded from the statistical analyses. Also excluded were species for which pathway of introduction was "unknown". Statistical analyses were only performed at the pathway category level and not at the subcategory level. The vectors of spread are not applicable for all taxonomic groups (e.g., nursery trade and vegetative reproduction are only applicable for plants). Therefore, including taxonomic group in the analyses of the vectors of spread led to many zero counts, and resulted in problems with the statistical models (e.g., algorithms did not converge). Taxonomic group was, therefore, not included as a variable in the statistical analyses of the vectors of spread.

Pearson's Chi squared tests were used to determine if the number of species that were introduced through the pathways, and that dispersed through the vectors of spread varied significantly from what would be expected based on chance alone (Crawley 2007).

To test the association between pathways of introduction (and vectors of spread) and the different factors (i.e., taxonomic groups, location and climate) 
or combinations of factors, the counts of species were analysed as contingency tables using log-linear models (Poisson error distribution and log-link, see Crawley 2007).

We classified the data using supervised machine learning techniques (Classification and Regression Tree analysis using the "Rpart" package in R; Therneau et al. (2015)) to identify the most prominent pathways of introduction for cities and to produce a decision tree. We selected tree-based model analyses as these are non-parametric, and output trees are simple and easy to interpret (Mohri et al. 2012). Furthermore, a variety of options are available for both continuous and categorical data. This study used taxonomic groups and the geographical and climatic characteristics of cities to predict which pathways of introduction were most likely to facilitate the introduction of alien species. Prior to conducting the analysis, we excluded all species for which pathways were "unknown", as well as species introduced through the corridor pathway (only one species record). We split the data into two equal subsets (i.e., the training dataset to build the model, and the testing dataset to validate the model). The training dataset was classified using binary recursive splitting; a process whereby the data are split into subgroups based on two potential outcomes, to produce a tree. This process was repeated until the tree was fully grown and the most likely pathways of introduction were identified. However, this can result in over-fitting of the data and as such can lead to inaccuracy in predictions. To minimise over-fitting of the output tree, we pruned the fully grown tree (Mohri et al. 2012). We used the testing dataset to validate the model and generated a confusion matrix to test the prediction accuracy of the model (see Online Resource 1-Supplementary Statistics).

All statistical analyses were conducted in $\mathrm{R}$ version 3.2.3 (R Core Team 2015).

\section{Results}

Pathway and vector prominence

For both, pathways of introduction $\left(\chi^{2}=2779\right.$, $d f=4, \quad p<0.001)$ and vectors of spread $\left(\chi^{2}=5749, d f=28, \quad p<0.001\right)$, species counts varied significantly from what would be expected by chance alone, indicating that some pathways and vectors facilitate the introduction and spread of species more than others. The escape and release pathways (intentional introductions) were more likely to facilitate the introduction of alien species. Alien species spread through natural means once introduced, with the most likely vectors of spread being unaided dispersal, endozoochory, and exozoochory (Figs. 2 and 4).

\section{Taxonomic groups (invertebrate, plants, vertebrates)}

There was a significant difference in the association between pathways and taxonomic group (Table 3 ). Escape and release were the most prominent pathways for plants and vertebrates (Figs. 2, 3). For invertebrates, the most prominent pathway was the stowaway pathway. Plant species were most likely intentionally introduced to cities for horticulture, while most invertebrates were introduced as stowaways on ships (through hull fouling, the release of ballast water or as a hitchhiker on the ship itself) (Fig. 3). Although not analysed statistically, unaided dispersal was the most prominent vector of spread for vertebrates and invertebrates. While unaided was also prominent for plants, endozoochory and water currents were the most prominent vectors of spread for these organisms (Fig. 4).

\section{Location (coastal, inland)}

We found a significant difference in the association between the pathways and city location (coastal and inland) but the patterns varied across taxonomic groups (Table 3). For invertebrates in coastal and

Table 3 The results from the log-linear models testing the differences in the associations between pathways ( 5 categories) and factors (taxonomic group-3 categories, location-2 categories, climate -7 categories,), and combinations of factors. The analyses show signification differences in associations between pathways and factors, as well as between pathways and a combination of factors

\begin{tabular}{lrrl}
\hline Factor & \multicolumn{1}{c}{$\chi^{2}$} & \multicolumn{1}{c}{$d f$} & \multicolumn{1}{l}{$p$} \\
\hline Taxonomic group & 901.1 & 8 & $<0.001^{*}$ \\
Location: taxonomic group & 28.3 & 8 & $<0.001^{*}$ \\
Climate: taxonomic group & 68.6 & 48 & $<0.05^{*}$ \\
\hline
\end{tabular}

* Significant difference in the association between pathways and factor 


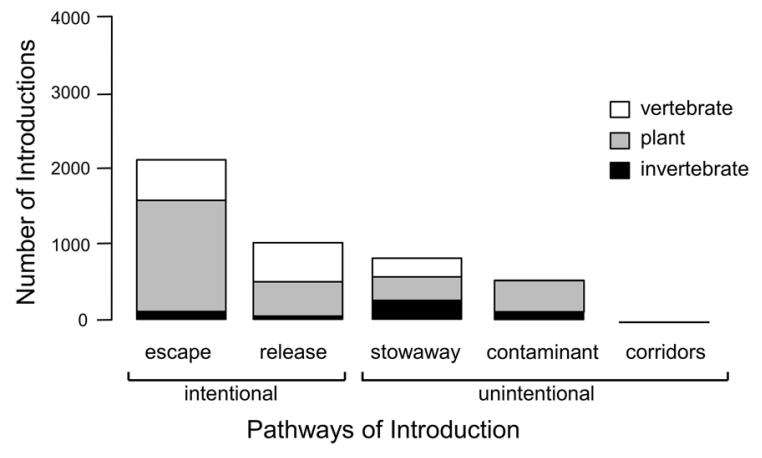

Fig. 2 The number of alien species introduced through the principal pathways of introduction for different taxonomic groups (invertebrates, plants and vertebrates). Species introduced through multiple pathways were counted for all pathways facilitating introduction. We found that counts for the pathways varied significantly from what was expected based on chance alone $\left(\chi^{2}=2779, d f=4, p<0.001\right)$

inland cities the stowaway pathway was the most prominent pathway (Fig. 5). Most invertebrates were unintentionally introduced to coastal cities as hitchhikers on ships or boats. The escape and release pathways were prominent for vertebrates in both coastal and inland cities (Fig. 5). Most vertebrates were introduced through the pet trade and for landscape/flora and fauna improvement. The most important pathway for plants, regardless of the location of a city, was the escape pathway (Fig. 5), with the majority of plants most likely introduced for horticulture (Fig. 3).

There was a significant difference in the association between the vectors of spread within a city and whether a city is coastal or inland (Table 4). However, regardless of the location of a city, the most prominent vector of spread within a city was through natural vectors (unaided dispersal) (Fig. 6).

\section{Climate}

We found a significant difference in the association between the pathways, climate and taxonomic group (Table 3). The prominence of the pathways differed for cities with different climates but the pattern varies depending on the taxonomic group. The escape

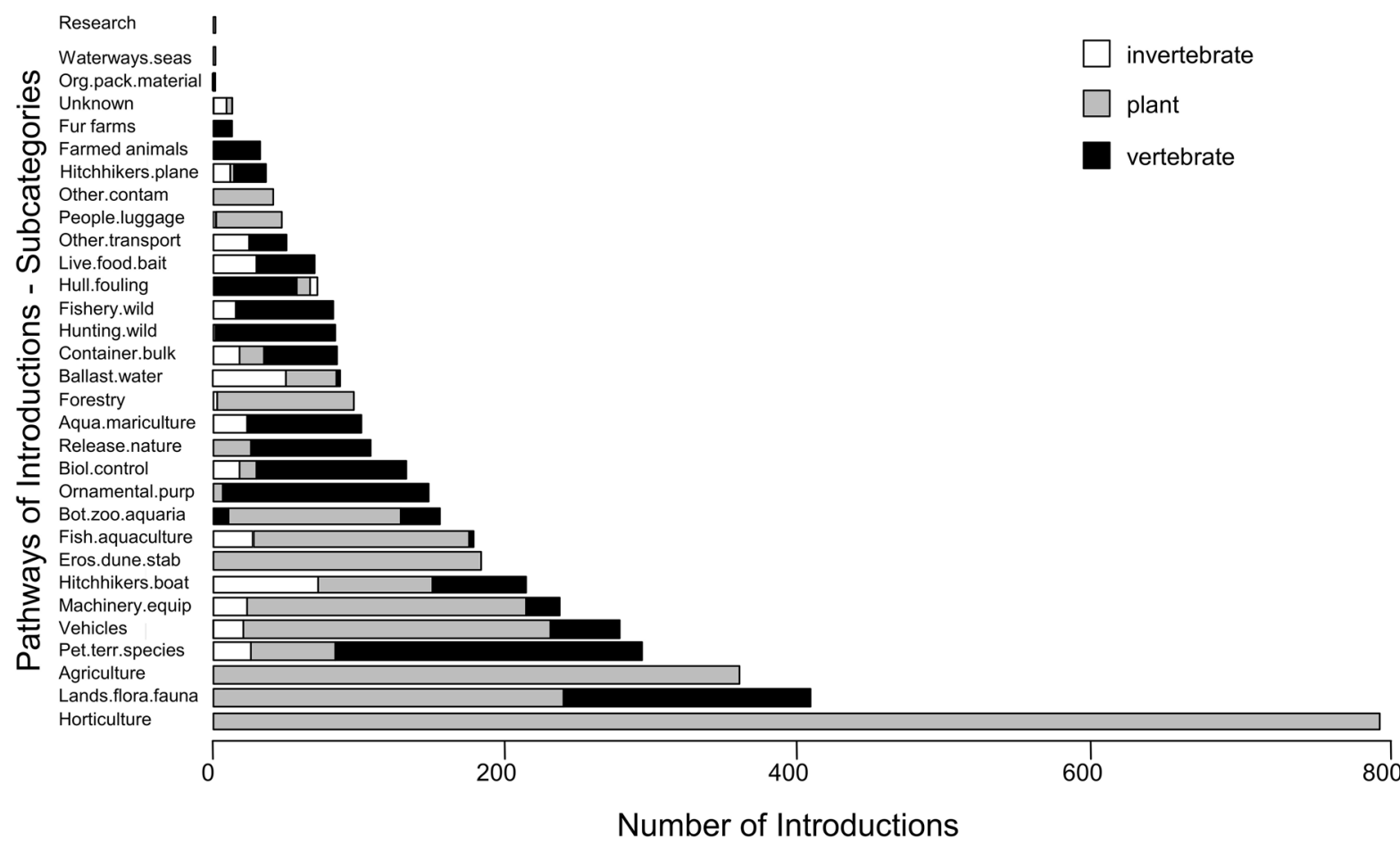

Fig. 3 The number of alien species introduced to cities through the pathways of introduction (subcategories of the CBD classification) for different taxonomic groups (invertebrates, plants and vertebrates). Species introduced through multiple pathways were counted for all pathways facilitating introduction. The full list of pathway subcategory names and abbreviations can be located in Table 1 


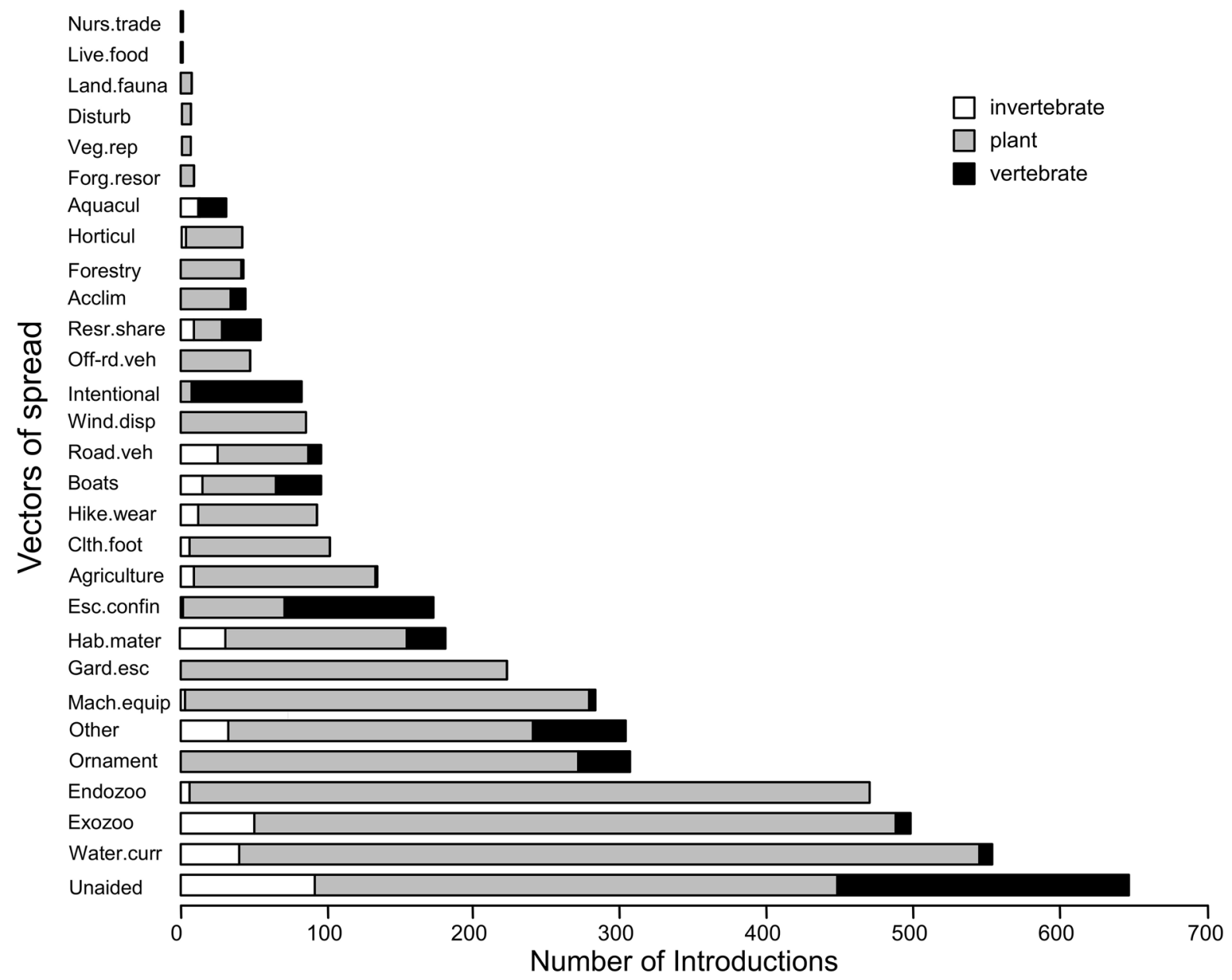

Fig. 4 The number of alien invertebrate, plant and vertebrate species spreading through the vectors of spread. Species spreading through multiple vectors were counted for all relevant vectors (see Table 2 for full list of vector names and abbreviations)

pathway was the most prominent pathway of introduction for plants regardless of the climate zone of a city. For vertebrates in cities with different climate zones, the most prominent pathways of introduction were either the escape or release pathways. The patterns observed for invertebrates varied across climate zones, with the stowaway, release and contaminant pathways being the most likely pathways to facilitate the introduction of alien species to cities with different climates.

There was a significant difference in the association between vectors and climate (Table 4). The pattern observed showed that in most climate zones unaided dispersal was the most prominent vector of spread. However, for cities with equatorial climates, endozoochory was the most prominent vector and for arid- snow climates, alien species are most often spread for ornamental purposes.

Prominence of pathways based on city characteristics

The results obtained from our model showed that the pathways most likely to facilitate the introduction of alien species depend on the taxonomic group of the alien species (Fig. 7). However, for some taxonomic groups, different pathways were more likely to facilitate the introduction of alien species to cities with different geographical and climatic characteristics. In the case of plants, depending on the climatic zone and whether ports were present in the city, the escape and release pathways were the most prominent 
Fig. 5 The number of alien species introduced to coastal and inland cities through the pathways of introduction for different taxonomic groups (invertebrates, plants and vertebrates). We found a significant difference in the association between pathways of introduction, taxonomic group and whether cities were located along the coast or inland $\left(\chi^{2}=28, d f=8\right.$, $p<0.001)$

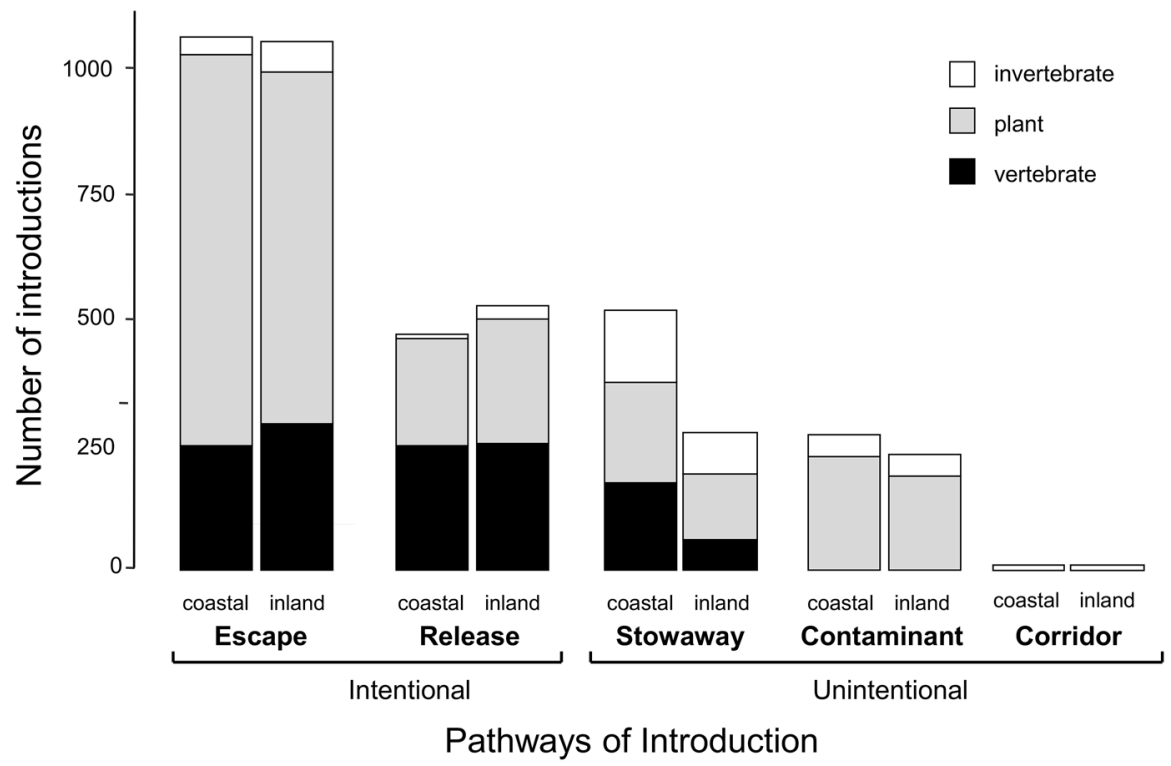

2017). The inaccuracy of predictions could be a result of insufficient predictors in the model to accurately predict the most probable pathways of introduction.

\section{Discussion}

The identification and prioritisation of pathways that facilitate the introduction of species in cities is essential for an effective response to biological invasions. This study focused on identifying the pathways most likely to facilitate the introduction of alien species to cities and the vectors of spread through which these species most probably move after introduction. We found that the intentional introduction of alien species to cities is more prominent than unintentional introductions, but that the subsequent spread of alien species occurs through natural mechanisms. Therefore, identifying and prioritising the pathways through which alien species are introduced to cities, and reducing the number of species introduced through the prioritised pathways, is pivotal for an effective response to biological invasions.

Even though the accuracy of the decision tree produced in this study is low, the results from the model predictions showed similar overall patterns as observed for contingency analyses for the prominence of pathways of introduction. We found that the most prominent pathway of introduction for plants was the escape pathway, regardless of the characteristics of a 


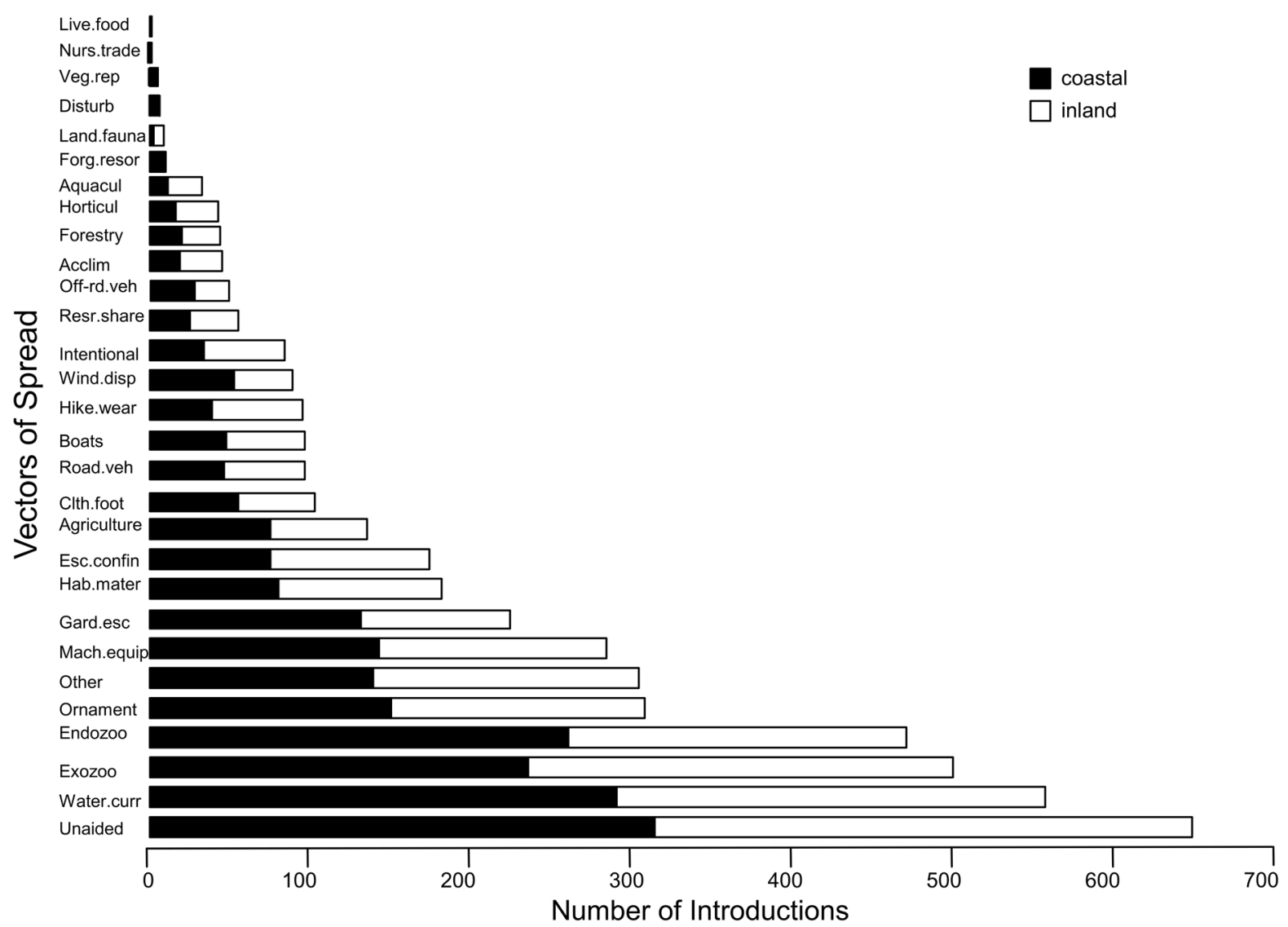

Fig. 6 The number of alien species spreading within coastal and inland cities through the vectors of spread (see Table 2 for full list of vector names and abbreviations). Species spreading through multiple vectors were recorded for all relevant vectors

city. Most plants that have escaped from cultivation were likely imported for the horticultural industry, and due to the substantial nature of this industry, it is likely that the escape pathway will continue to be important (Burt et al. 2007; Dehnen-Schmutz et al. 2007; Novoa et al. 2015; Visser et al. 2016; Faulkner et al. 2016a; Cronin et al. 2017). This is despite voluntary codes of practice for the horticultural industry outlined by the International Plant Protection Convention (IPCC) and the CBD (Schrader and Unger 2003), and the regulatory frame-works in place in some countries (e.g., South Africa, the National Environmental: Biodiversity Act No. 10 of 2004). A lack of awareness regarding invasive alien plants persists among some horticulturalists (suppliers and consumers) potentially leading to the continued sale of invasive plants (Drew et al. 2010; Cronin et al. 2017). This needs to be addressed to prevent the sale of harmful alien plant of spread. We found a significant difference in the association between the vectors of spread and whether a city was coastal or inland $\left(\chi^{2}=5749, d f=28, p<0.001\right)$

species. Although this study highlights the escape pathway as the most prominent pathway of introduction for plants, a study conducted by Pergl et al. (2017) showed that alien plant species introduced through the release, corridor and unaided pathways were most likely to have ecological impacts.

The patterns observed in the prominence of pathways for invertebrates showed that different pathways should be targeted for prevention and management responses based on a city's characteristics. For example, the stowaway pathway should be prioritised for management in cities with maritime ports while the contaminant (unintentional) pathway should be prioritised for cities without ports. Invertebrates were predominantly introduced as stowaways on ships or boats to cities with ports. To effectively respond to aquatic invertebrate introductions in cities with ports, coordinated strategies need to be implemented to 


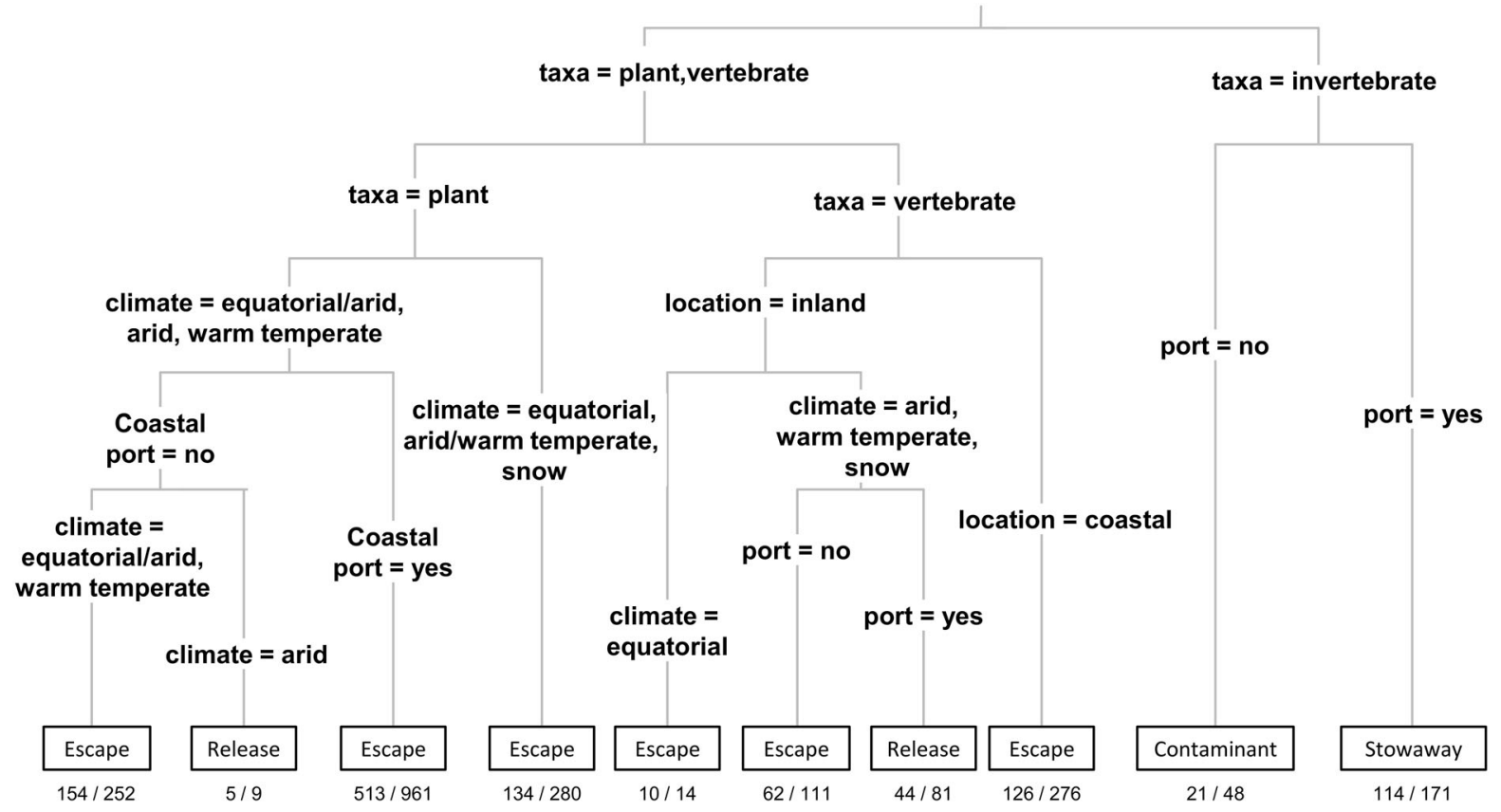

Fig. 7 The decision tree produced using the training dataset shows, at terminal nodes, the most likely pathways to facilitate the introduction of alien species based on the characteristics of the cities and the taxonomic group of the alien species. The numbers below the terminal nodes indicate the number of

strategically and effectively prevent introductions (Kölzsch and Blasius 2011; Bacon et al. 2012; Faulkner et al. 2016b; Cope et al. 2016).

Similar to the case of invertebrates, management strategies for alien vertebrate species need to be based on the prominent pathways of introduction determined by the characteristics of the city. The intentional (escape and release) pathways are most prominent regardless of the characteristics of a city. Alien vertebrate species are predominantly introduced for the pet trade (Brown 2006; Kraus 2007). The increasing popularity of the pet trade will likely mean that this pathway will continue to be important for the introduction of alien vertebrate species. The management of the pet-trade industry hinges on the regulation of species through permits. The problem with permit issuing is that permits centre on voluntary compliance to guidelines and codes of practice (van Wilgen et al. 2008; Essl et al. 2015; Hulme 2015). Permits are only required for owners to be in possession of said species but do not stipulate disposal procedures in the event that the pet owners no longer wish to retain their pets (van Wilgen et al. 2010). In some instances, owners species recorded for the particular pathway in relation to the total number of species recorded for cities with those particular characteristics across all pathways. The climate zones follow our categorisation system $(\mathrm{A}=$ equatorial, $\mathrm{B}=$ arid, $\mathrm{C}=$ warm temperate and $\mathrm{D}=$ snow-Kottek et al. 2006)

release or dispose of pets if their value decreases, or if they tire of taking care of these pets (van Wilgen et al. 2010). Follow-up procedures regarding the codes of best practice depend on the legislation and implementation of these codes in individual countries. There needs to be stricter traceability and accountability for negligence concerning the release or disposal of alien vertebrate species kept as pets (Hulme et al. 2008). Alternatively, a tax or levy could be charged to fund the control of escaped exotics. However, this can potentially be disadvantageous to the pet trade industry, as the incurred cost could discourage consumers from purchasing exotic pet species.

\section{Conclusion}

To curb the introduction of alien species we recommend that prevention strategies take into consideration all the complex factors that influence alien species introductions (Pergl et al. 2017). The decision tree presented here provides decision makers with a starting point to prioritise the pathways of introduction 
for management based on the taxonomic group of interest as well as the different characteristics of the city; however, further detailed research will be required for decision makers to assign priorities to alien species and the pathways of introduction.

Acknowledgements This research was funded by the South African National Department of Environmental Affairs through its funding of the South African National Biodiversity Institute's Invasive Species Programme. An early version of this paper was presented at a workshop on "Non-native species in urban environments: Patterns, processes, impacts and challenges" that was hosted and co-funded by the DST-NRF Centre of Excellence for Invasion Biology in Stellenbosch in November 2016. Many participants at the workshop provided useful comments and suggestions which improved the paper. We thank The Global Invasive Species Database for the provision of data, Desika Moodley and Osadolor Ebhuoma for their technical assistance, and two anonymous reviewers for their comments and suggestions.

\section{References}

Bacon SJ, Bacher S, Aebi A (2012) Gaps in border controls are related to quarantine alien insect invasions in Europe. PLoS ONE 7:e47689

Blackburn TM, Pyšek P, Bacher S, Carlton JT, Duncan RP, Jarošik V, Wilson JRU, Richardson DM (2011) A proposed unified framework for biological invasions. Trends Ecol Evol 26:333-339

Blackie RR, Sunderland TC (2015) Mapping landscape guidelines and principles to the Aichi targets. CIFOR 123:1-4

Brown R (2006) Exotic pets invade United States ecosystems: legislative failure and a proposed solution. Indiana Law J 81:713-731

Burt JW, Muir AA, Piovia-Scott J, Veblen KE, Chang AL, Grossman JD, Weiskel HW (2007) Preventing horticultural introductions of invasive plants: potential efficacy of voluntary initiatives. Biol Invasions 9:909-923

Cope RC, Ross VJ, Wittmann TA, Prowse TAA, Cassey P (2016) Intergrative analysis of the physical transport network into Australia. PLoS ONE 11:e0148831

Crawley M (2007) The R book. Wiley, Chichester

Cronin K, Kaplan H, Gaertner M, Irlich I, Hoffman TM (2017) Aliens in the nursery: assessing the attitudes of nursery managers to invasive species regulations. Biol Invasions 19:925-937

Dehnen-Schmutz K, Touza J, Perrings C, Williamson M (2007) The horticultural trade and ornamental plant invasions in Britain. Conserv Biol 21:224-231

Demographia (2014) Demographia world urban areas (built-up urban areas or world agglomerations) 10th annual edition. http://www.demographia.com/. Accessed 23 Aug 2015

Drew J, Anderson N, Andow D (2010) Conundrums of a complex vector for invasive species control: a detailed examination of the horticultural industry. Biol Invasions 12:2837-2851
ESRI (2006) ArcGIS 9.3. Environmental Research Systems Institute, Inc, Redlands, CA

Essl F, Bacher S, Blackburn TM, Booy O et al (2015) Crossing frontiers in tackling pathways of biological invasions. Bioscience 65:769-782

Faulkner KT, Robertson MP, Rouget M, Wilson JRU (2016a) Understanding and managing the introduction pathways of alien taxa: South Africa as a case study. Biol Invasions 18:73-87

Faulkner KT, Robertson MP, Rouget M, Wilson JRU (2016b) Border control for stowaway alien species should be prioritised based on variations in establishment debt. J Environ Manage 180:301-309

Ficetola GF, Thuiller W, Padoa-Schioppa E (2009) From introduction to the establishment of alien species: bioclimatic differences between presence and reproduction localities in the slider turtle. Divers Distrib 15:108-116

Gallardo B, Aldridge DC (2013) The 'dirty dozen': socio-economic factors amplify the invasion potential of 12 high-risk aquatic invasive species in Great Britain and Ireland. J Appl Ecol 50:757-766

GBIF (2016) Global Biodiversity Information Facility. http:// www.gbif.org/. Accessed 01 Dec 2016

GISD (2016) Global Invasive Species Database. Invasive Species Specialist Group (ISSG) of the IUCN Species Survival Commission. http://www.issg.org/database. Accessed 9 June 2016

Gotzek D, Axen HJ, Suarez AV, Helms Cahan S, Shoemaker D (2015) Global invasion history of the tropical fire ant: a stowaway on the first global trade routes. Mol Ecol 24:374-388

GRIIS (2016) Global Register of Introduced and Invasive Species. http://www.griis.org/. Accessed 15 Nov 2016

Hansen MJ, Clevenger AP (2005) The influence of disturbance and habitat on the presence of non-native plant species along transport corridors. Biol Conserv 125:249-259

Hulme PE (2006) Beyond control: wider implications for the management of biological invasions. J Appl Ecol 43:835-847

Hulme PE (2015) Invasion pathways at a crossroads: policy and research challenges for managing alien species introductions. J Appl Ecol 52:1418-1424

Hulme PE, Bacher S, Kenis M et al (2008) Grasping at the routes of biological invasions: a framework for integrating pathways into policy. J Appl Ecol 45:403-414

Katsanevakis S, Zenetos A, Belchior C, Cardoso A-C (2013) Invading European seas: assessing pathways of introduction of marine aliens. Ocean Coast Manage 76:64-74

Kenis M, Auger-Rozenberg M-A, Roques A et al (2009) Ecological effects of invasive alien insects. Biol Invasions 11:21-45

Kölzsch A, Blasius B (2011) Indications of marine bioinvasion from network theory. Eur Phys J B 84:601-612

Kottek M, Grieser J, Beck C, Rudolf B, Rubel F (2006) World Map of the Köppen-Geiger climate classification updated. Meteorol Z 15:259-263

Kraus F (2007) Using pathway analysis to inform prevention strategies for alien reptiles and amphibians. Manag Vertebr Invasive Species 21:94-103 
Kumschick S, Richardson DM (2013) Species-based risk assessments for biological invasions: advances and challenges. Divers Distrib 19:1095-1105

Leung B, Springborn MR, Turner JA, Brockerhoff EG (2014) Pathway-level risk analysis: the net present value of an invasive species policy in the US. Front Ecol Environ 12:273-279

McGeoch MA, Genovesi P, Bellingham PJ, Costello MJ, McGrannachan C, Sheppard A (2016) Prioritizing species, pathways, and sites to achieve conservation targets for biological invasions. Biol Invasions 18:299-314

McLean P, Gallien L, Wilson JRU, Gaertner M, Richardson DM (2017) Small urban centres as launching sites for plant invasions in natural areas: insights from South Africa. Biol Invasions. doi:10.1007/s10530-017-1600-4

Mohri M, Rostamizadeh A, Talwalkar A (2012) The foundations of machine learning. The MIT Press, Cambridge

Novoa A, Le Roux JJ, Robertson MP et al (2015) Introduced and invasive cactus species: a global review. AoB Plants 7:plu078. doi:10.1093/aobpla/plu078

Pergl J, Pyšek P, Bacher S et al (2017) Troublling travellers: are economically harmful alien species associated with particular introduction pathways? NeoBiota 32:1-20

Pimentel D, McNair S, Janecka J et al (2001) Economic and environmental threats of alien plant, animal and microbe invasions. Agric Ecosyst Environ 84:1-20

Puth LM, Post DM (2005) Studying invasions: have we missed the boat? Ecol Lett 8:715-721

Pyšek P, Richardson DM (2010) Invasive species, environmental change and management, and health. Annu Rev Environ Resour 35:25-55

R Core Team (2015) R: a language and environment for statistical computing. $r$ foundation for statistical computing. Vienna, Austria. http://www.R-project.org/

Reaser JK, Meyerson LA, Von Holle B (2008) Saving camels from straws: how propagule pressure-based prevention policies can reduce the risk of biological invasion. Biol Invasions 10:1085-1098

Richardson DM, Pyšek P, Rejmánek M et al (2000) Naturalization and invasion of alien plants: concepts and definitions. Divers Distrib 6:93-107

Richardson DM, Pyšek P, Carlton JT (2010) A compendium of essential concepts and terminology in invasion ecology. In: Richardson DM (ed) Fifty years of invasion ecology: the legacy of Charles Elton. Wiley, Oxford. doi:10.1002/ 9781444329988.ch30
Saul W-C, Roy HE, Booy O, Carnevali L, Chen H-J, Genovesi P, Harrower CA, Hulme PE, Pagad S, Pergl J, Jeschke JM (2016) Assessing patterns in introduction pathways of alien species by linking major invasion databases. J Appl Ecol 54:657-669

Scalera R, Genovesi P, Booy O et al. (2016) Technical report: progress towards pathways prioritization in compliance to Aichi Target 9. Information documented presented at SBSTTA $20 \mathrm{UNEP/CBD/SBSTTA/20/INF/5,} \mathrm{the} \mathrm{twenti-}$ eth meeting of the CBD's Subsidiary Body on Scientific, Technical and Technological Advice, Montreal, Canada, 25-30 April 2016

Schrader G, Unger J-G (2003) Plant quarantine as a measure against invasive alien species: the framework of the International Plant Protection Convention and the plant health regulations in the European Union. Biol Invasions 5:357-364

Therneau T, Atkinson B, Ripley B (2015) Rpart: recursive partitioning and regression trees. R package version 4.1.10. https://CRAN.R-project.org/package=rpart

United Nations, Department of Economic and Social Affairs, Population Division (2014) World urbanization prospects: the 2014 revision, CD-ROM edition. https://esa.un.org/ unpd/wup/cd-rom/. Accessed 23 Aug 2015

Van Wilgen NJ, Richardson DM, Baard EHW (2008) Alien reptiles and amphibians in South Africa: towards a pragmatic management strategy. S Afr J Sci 104:13-20

Van Wilgen NJ, Wilson JRU, Elith J et al (2010) Alien invaders and reptile traders: what drivers the live animal trade in South Africa? Anim Conserv 13(Suppl 1):24-32

Vila M, Basnou C, Pyšek P, Josefsson M et al (2010) How well do we understand the impacts of alien species on ecosystem services? A pan-European, cross-taxa assessment. Front Ecol Environ 8:135-144

Visser V, Wilson JRU, Fish L, Brown C, Cook GD, Richardson DM (2016) Much more give than take: South Africa as a major donor but infrequent recipient of invasive non-native grasses. Glob Ecol Biogeogr 25:679-692

von der Lippe M, Kowarik I (2008) Do cities export biodiversity? Traffic as dispersal vector across urban-rural gradients. Divers Distrib 14:18-25

Wilson JRU, Dormontt EE, Prentis PJ et al (2009) Something in the way you move: dispersal pathways affect invasion success. Trends Ecol Evol 24:136-144

Woodford DJ, Richardson DM, MacIsaac HJ et al (2016) Confronting the wicked problem of managing biological invasions. NeoBiota 31:63-68 
Fig. 1: The number of species within each sub-group for the taxonomic groups (arthropod=8, annelid=3, bryozoan $=1$, insect $=18$, mollusc $=9$, seastar $=1$, tunicate $=3$, aquatic plant $=17$, grass $=18$, herb $=35$, shrub $=23$, succulent $=2$, tree $=26$, tree-shrub $=11$, vine $=11$, vineclimber=5, aquatic plant-succulent=1, climber=2, bird=14, fish=24, mammal=16, reptile=4, amphibian=2).

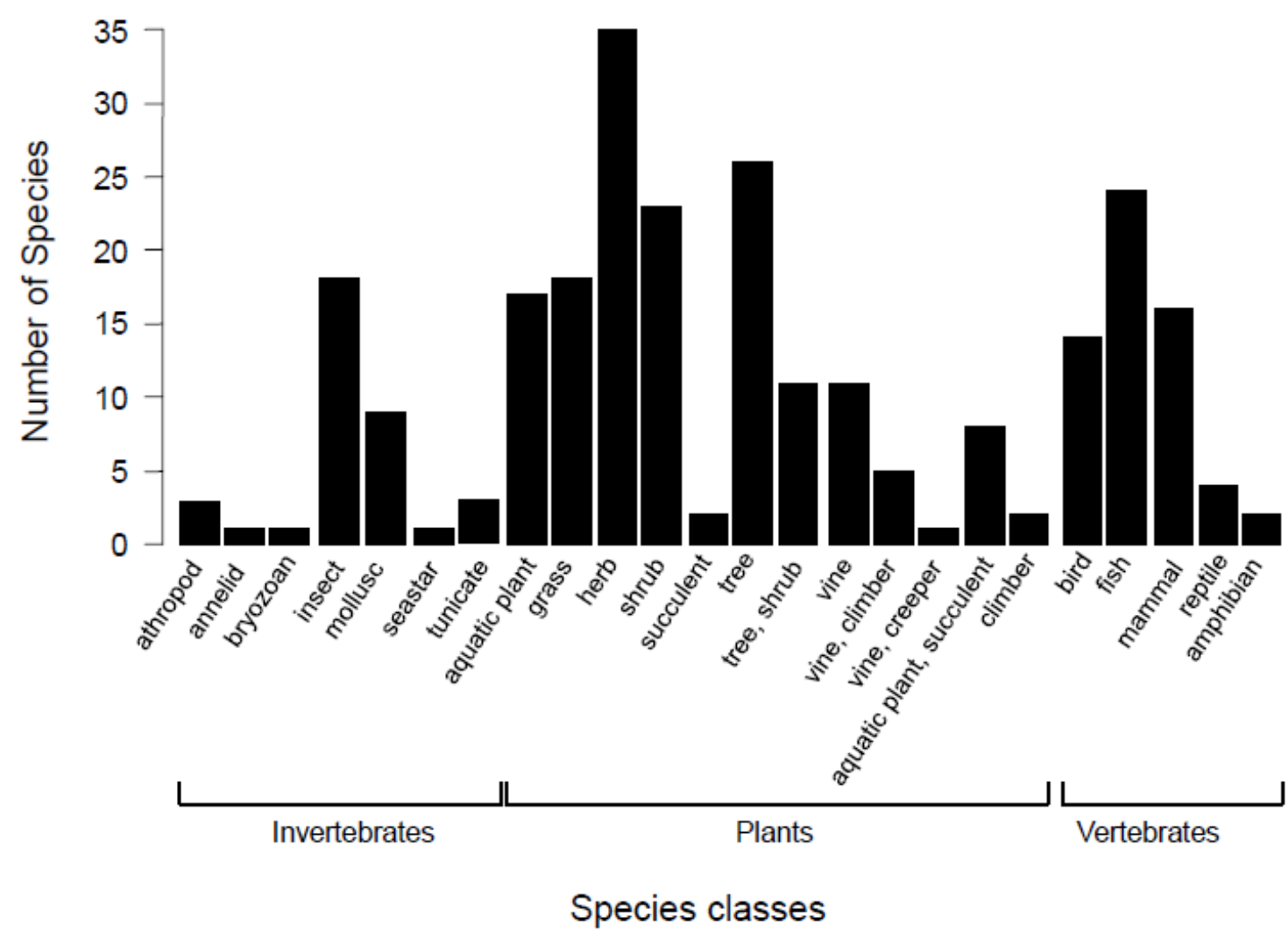


Fig. 2: The number of alien species occupying different environments (terrestrial=20, freshwater $=6$, marine $=14$, freshwater-terrestrial $=8$, marine-brackish-freshwater $=1$, marineterrestrial=1).

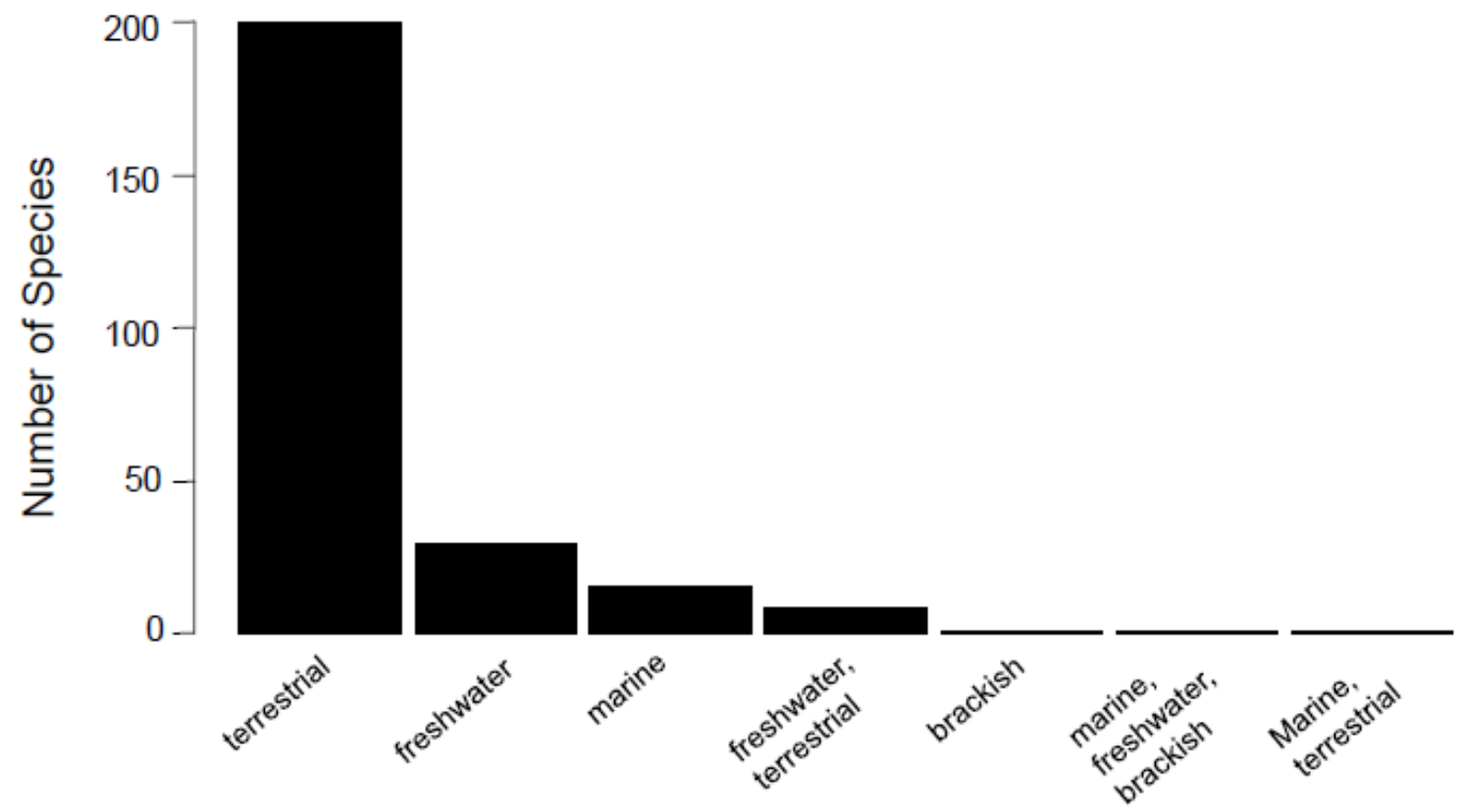

Environment 


\section{CART analysis - supplementary statistics}

Table 1: The results of the confusion matrix produced in the CART analysis showing the prediction accuracy of the model produced. Prediction accuracy was calculated as the percentage of correct prediction in relation to the total number of observations for each pathway.

\begin{tabular}{l|llll|l}
\hline \multirow{2}{*}{$\begin{array}{l}\text { Predicted } \\
\text { results }\end{array}$} & \multicolumn{3}{l}{ True observations } & & Prediction \\
\cline { 2 - 5 } & Contaminant & Escape & Release & Stowaway & $\begin{array}{l}\text { Accuracy } \\
(\%)\end{array}$ \\
\hline Contaminant & 8 & 10 & 12 & 18 & 16.7 \\
Escape & 178 & 926 & 423 & 367 & 48.9 \\
Release & 5 & 38 & 42 & 5 & 46.7 \\
Stowaway & 32 & 64 & 26 & 49 & 28.7 \\
\hline
\end{tabular}

"all records for "unknown" pathways were removed prior to analysis

*corridor pathway was excluded from analysis as there was only 1 record 